\title{
Analysis of Current Variation with Work Function Variation in L-Shaped Tunnel-Field Effect Transistor
}

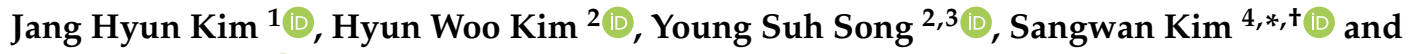 \\ Garam Kim ${ }^{5, *,+}$ (D) \\ 1 School of Electrical Engineering, Pukyong National University, Busan 48513, Korea; janghyun@pknu.ac.kr \\ 2 Department of Electrical and Computer Engineering, Seoul National University, Seoul 08826, Korea; \\ hyunoo1218@naver.com (H.W.K.); sys1413@snu.ac.kr (Y.S.S.) \\ 3 Department of Computer Science, Korea Military Academy, Seoul 01805, Korea \\ 4 Department of Electrical and Computer Engineering, Ajou University, Suwon 16499, Korea \\ 5 Department of Electronic Engineering, Myongji University, Yongin 17058, Korea \\ * Correspondence: sangwan@ajou.ac.kr (S.K.); garamkim@mju.ac.kr (G.K.) \\ + Both authors contributed equally to this manuscript.
}

Received: 16 July 2020; Accepted: 14 August 2020; Published: 15 August 2020

\begin{abstract}
In this paper, an investigation is performed to analyze the L-shaped tunnel field-effect transistor (TFET) depending on a gate work function variation (WFV) with help of technology computer-aided design (TCAD) simulation. Depending on the gate voltage, the three variations occur in transfer curves. The first one is the on-state current $\left(I_{\mathrm{ON}}\right)$ variation, the second one is the hump current $\left(I_{\mathrm{HUMP}}\right)$ variation, and the last one is ambipolar current $\left(I_{\mathrm{AMB}}\right)$ variation. According to the simulation results, the $I_{\mathrm{ON}}$ variation is sensitive depending on the size of the tunneling region and could be reduced by increasing the tunneling region. However, the $I_{\mathrm{HUMP}}$ and $I_{\mathrm{AMB}}$ variations are relatively irrelevant to the size of the tunneling region. In order to analyze the cause of this difference, we investigated the band-to-band tunneling (BTBT) rate according to WFV cases. The results show that when $I_{\mathrm{ON}}$ is formed in L-shaped TFET, the BTBT rate relies on the WFV in the whole region of the gate because the tunnel barrier is formed in the entire area where the source and the gate meet. On the other hand, when the $I_{\mathrm{HUMP}}$ and $I_{\mathrm{AMB}}$ are formed in L-shaped TFET, the BTBT rate relies on the WFV in the edge of the gate.
\end{abstract}

Keywords: tunnel field-effect transistor (TFET); L-shaped TFET; high- $/$ /metal gate (HKMG); work-function variation (WFV); band-to-band tunneling; on-state current $\left(I_{\mathrm{ON}}\right)$ variation; hump current $\left(I_{\mathrm{HUMP}}\right)$ variation; ambipolar current $\left(I_{\mathrm{AMB}}\right)$ variation

\section{Introduction}

Recently, an L-shaped tunnel field-effect transistor (TFET) has attracted the attention of a lot of researchers as a substitutional device for a metal-oxide-semiconductor (MOS) field-effect transistor (MOSFET) [1-6]. The L-shaped TFET features a mesa-shaped structure and an intrinsic Si region located between the source and gate dielectric layer to obtain high band-to-band tunneling (BTBT) due to the larger tunneling area than the planar TFET. The L-shaped TFET has remarkable advantages for low-voltage operation due to its small subthreshold swing $(S)$ of less than $60 \mathrm{mV} / \mathrm{dec}$, low-level OFF-state current $\left(I_{\mathrm{OFF}}\right)$ and high complementary MOS (CMOS) compatibility [7-10]. Based on the characteristics, the electrical performance of the L-shaped TFET can be more improved dramatically by applying the high-k/metal gate (HKMG) technology [11-13]. Thus, it is expected that the L-shaped TFET is applicable to the real industry. However, the application of HKMG brings a work-function (WF) variation (WFV) issue due to the non-uniformity of metal gate grains in orientation depending 
on the fabrication processes [14-17]. Therefore, in order to apply the TFET to the real application, the WFV in TFET should be investigated. Although there are several studies about the WFV effects on TFET, they have some common issues. The mentioned papers have focused on variation in electrical characteristics (e.g., threshold voltages $\left(V_{\mathrm{T}}\right)$ and ON-state current $\left.\left(I_{\mathrm{ON}}\right)\right)$ in general structures (e.g., planar, fin, nanowire) and have not proposed the improvement of WFV in TFET [14-18].

This paper aims to study the effects of WFV in L-shaped TFET with the help of technology computer-aided design (TCAD) simulation. The L-shaped TFET is expected to improve the WFV due to the large tunneling area. Because the WFV has been studied, we know that the channel area and the WFV have a high correlation $[19,20]$. The contents of this paper are as follows. In Section II, the structure and dimension of the studied L-shaped TFET are explained. The WFV induced by the grain of the metal gate is set reflecting the actual gate physical properties. In Section III, the quantitative analysis is performed by confirming the location of metal grains and BTBT rate to monitor the variation of $I_{\mathrm{ON}}$, hump current $\left(I_{\mathrm{HUMP}}\right)$ and ambipolar current $\left(I_{\mathrm{AMB}}\right)$ of the L-shaped TFET.

\section{Device Structure}

The structure of L-shaped TFET for WFV analysis is shown in Figure 1a. It features that thin intrinsic $\mathrm{Si}$ is deposited to restrict tunnel width for enhancing BTBT. All of the source, drain and channel materials consist of Si. The body thickness $\left(T_{\mathrm{B}}\right)$ of $20 \mathrm{~nm}$, the lateral channel length $\left(L_{\mathrm{ch}}\right)$ of $50 \mathrm{~nm}$, vertical tunneling thickness ( $\left.L_{\text {tun }}\right)$ of $6 \mathrm{~nm}$ and the $\mathrm{SiO}_{2}$ gate oxide thickness $\left(T_{\mathrm{OX}}\right)$ of $1 \mathrm{~nm}$ are applied. p-type body doping $\left(N_{\mathrm{B}}\right)$ of $1 \times 10^{17} \mathrm{~cm}^{-3}$ is set. Then, both Si source and drain doping concentrations $\left(N_{\mathrm{S}}, N_{\mathrm{D}}\right)$ are set as $1 \times 10^{20} \mathrm{~cm}^{-3}$ with opposite doping types Boron and Arsenic. For confirming the effect for the area of the tunneling barrier, the source height $\left(H_{\mathrm{S}}\right)$ is varied from $10 \mathrm{~nm}$ to $50 \mathrm{~nm}$. The gate area is split into $10 \mathrm{~nm} \times 10 \mathrm{~nm}$ units considering the grain size of TiN and it is assumed to be an identical square shape [21]. In the real fabrication process, the sputtered TiN is mainly crystallized in $<200>(60 \%)$ and in $<111>(40 \%)$ which correspond to $4.6-\mathrm{eV}$ and 4.4-eV WFs, respectively [19,22]. In order to compare with planar TFET as a control group, the planar TFET has the same parameter for $W, T_{\mathrm{B}}, L_{\mathrm{ch}}, N_{\mathrm{S}}, N_{\mathrm{D}}$ and $N_{\mathrm{B}}$ (Figure $1 \mathrm{~b}$ ). All the specifications are summarized in Table 1.

(a)

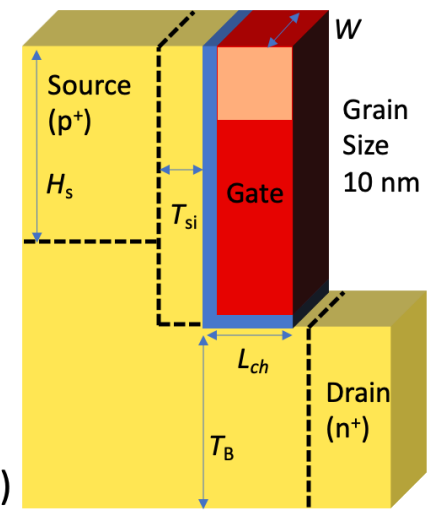

(b)

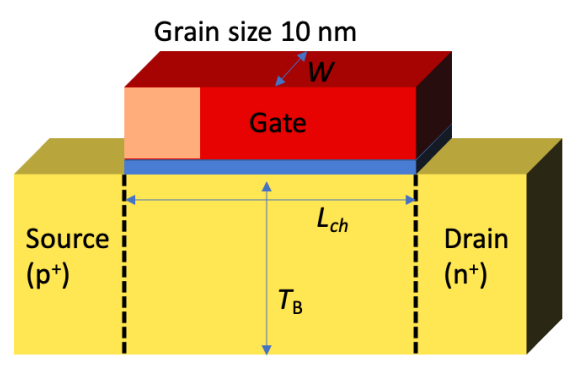

Figure 1. Schematic diagram of (a) the L-shaped tunnel field-effect transistor (TFET) and (b) the planar TFET. The L-shaped TFET features a vertical- band-to-band tunneling (BTBT) (parallel to the gate-field direction) in the intrinsic Si layer. 
Table 1. Device parameters of devices used for technology computer-aided design (TCAD) simulation.

\begin{tabular}{|c|c|c|}
\hline Parameters & \multicolumn{2}{|c|}{ Value } \\
\hline Device & L-shaped TFET & Planar TFET \\
\hline Source doping concentration $\left(N_{S}\right)$ & \multicolumn{2}{|c|}{$10^{20} \mathrm{~cm}^{-3}$ (p-type) } \\
\hline Drain doping concentration $\left(N_{\mathrm{D}}\right)$ & \multicolumn{2}{|c|}{$10^{20} \mathrm{~cm}^{-3}$ (n-type) } \\
\hline Body doping concentration $\left(N_{\mathrm{B}}\right)$ & \multicolumn{2}{|c|}{$10^{17} \mathrm{~cm}^{-3}$ (p-type) } \\
\hline Channel length $\left(L_{\mathrm{ch}}\right)$ & \multicolumn{2}{|c|}{$50 \mathrm{~nm}$} \\
\hline Channel width $(W)$ & \multicolumn{2}{|c|}{$30 \mathrm{~nm}$} \\
\hline Metal grain size & \multicolumn{2}{|c|}{$10 \mathrm{~nm}$} \\
\hline Intrinsic layer thickness $\left(T_{\mathrm{Si}}\right)$ & $6 \mathrm{~nm}$ & none \\
\hline Gate oxide thickness ( $\left.T_{\mathrm{OX}}\right)$ & \multicolumn{2}{|c|}{$1 \mathrm{~nm}$} \\
\hline Drain voltage $\left(V_{\mathrm{D}}\right)$ & \multicolumn{2}{|c|}{$1.0 \mathrm{~V}$} \\
\hline Source height $\left(H_{\mathrm{S}}\right)$ & \multicolumn{2}{|c|}{ varied } \\
\hline
\end{tabular}

The characteristics of the L-shaped TFET is simulated by the Synopsys Sentaurus ${ }^{\mathrm{TM}}$. The Shockley-Read-Hall (SRH) and dynamic nonlocal BTBT model are used for accurate characteristics $[23,24]$. The dynamic nonlocal BTBT model is essential to examine lateral- and verticalBTBT in the L-shaped TFET, since it can dynamically determine and calculate all tunneling paths based on the energy band profile [3,25-27]. In detail, the BTBT model calibrated with experimental results [28]. The BTBT generation rate per unit volume $(\mathrm{G})$ defined as

$$
G=A\left(\frac{F}{F_{0}}\right)^{P} \exp \left(-\frac{B}{F}\right)
$$

in the uniform electric field limit where $F_{0}=1 \mathrm{~V} / \mathrm{m}$ and $P=2.5$ for indirect tunneling [29]. The prefactor $(A)$ and the exponential factor $(B)$ are Kane parameters while the $F$ is electric field [30,31]. The extracted $A$ and $B$ parameters of the BTBT model in Si TFET are $4 \times 10^{14} \mathrm{~cm}^{-1} \mathrm{~s}^{-1}$ and $9.9 \times 10^{6} \mathrm{~V} / \mathrm{cm}$, respectively. Additionally, modified local density approximation (MLDA) is used for including quantum phenomena [32,33]. The MLDA model is needed to calculate the confined carrier distributions, especially inside the ultra-thin intrinsic Si tunnel region in which BTBT occurs. All the models are summarized in Table 2.

Table 2. Models in TCAD simulation.

\begin{tabular}{cc}
\hline Definition & Model \\
\hline Bandgap narrowing & Old slot boom \\
Fermi Statistic & Fermi \\
Phonon scattering & Constant mobility \\
Multi-valley for quantum confinement & MLDA \\
SRH recombination & SRH/TAT \\
Nonlocal BTBT & Band to Band \\
WFV & $4.6 / 4.4 \mathrm{eV}(60 \% / 40 \%)$ (Random generation) \\
\hline
\end{tabular}

\section{Results and Discussion}

Figure 2a shows the transfer characteristics of the planar TFET and L-shaped TFET with various source heights $\left(H_{\mathrm{S}}\right)$ at $1.0 \mathrm{~V}$ of drain voltages $\left(V_{\mathrm{DS}}\right)$. In each case of $H_{\mathrm{S}}$, the 30 samples are simulated, and each sample contains randomly generated TiN grains in the gate. The $I_{\mathrm{ON}}$ of the L-shaped TFET increases as the $H_{S}$ increases. The result shows that the L-shaped TFET can improve the weak drivability of $I_{\mathrm{ON}}$, which is a weakness of TFET. In addition, the average $S\left(S_{\text {avg }}\right)$, defined as the average inverse slope of the transfer curve while $I_{\mathrm{D}}$ changes from $10^{-15} \mu \mathrm{A} / \mu \mathrm{m}$ to $10^{-11} \mu \mathrm{A} / \mu \mathrm{m}$, is shown from 35 to $45 \mathrm{mV} /$ decade for the L-shaped TFET which means that the L-shaped TFET suggests possible applications for the low power operation [34,35]. In transfer curves, we measure three regions: $I_{\mathrm{ON}}, I_{\mathrm{HUMP}}$ and $I_{\mathrm{AMB}}$ variations. Each variation extracted the difference between the maximum and 
minimum values of the $V_{\mathrm{GS}}$ values represented by each sample when the $I_{\mathrm{ON}}, I_{\mathrm{HUMP}}$ and $I_{\mathrm{AMB}}$ are formed. Firstly, the $I_{\mathrm{ON}}$ variation is investigated. The variation of $I_{\mathrm{ON}}$ is extracted from Figure $2 \mathrm{a}$ at $10^{-9} \mathrm{~A} / \mu \mathrm{m}$ of drain current $\left(I_{\mathrm{D}}\right)$. For the $I_{\mathrm{ON}}$ variation, it is found that the greater the $H_{\mathrm{S}}$ value, the smaller the $I_{\mathrm{ON}}$ variation and the $I_{\mathrm{ON}}$ variation of the L-shaped TFET could be reduced compared with that of the planar TFET (Figure 2b). For the planar TFET, the tunnel barrier that determines the current, is formed only in the area adjacent to the source and channel $[14,36]$. This means that the $I_{\mathrm{ON}}$ variation in planar TFET relies on the WFV in areas adjacent to the source, not on the whole area of the gate. However, for the L-shaped TFET, the tunneling area affected by the WFV is relatively wider than that of the planar TFET because the tunnel barrier is formed in the entire area where the source and gate meet [1]. Figure 3a shows a sample produced by a random WFV. Inside the gate, $4.4 \mathrm{eV}$ and $4.6 \mathrm{eV}$ grains are placed. Based on this sample, the vertical-BTBT generated in the source area can be found to be high where the grain of $4.4 \mathrm{eV}$ is located (Figure $3 \mathrm{~b}$ ). In other words, when the tunnel barrier has a large area, the BTBT rate can have an average effect.
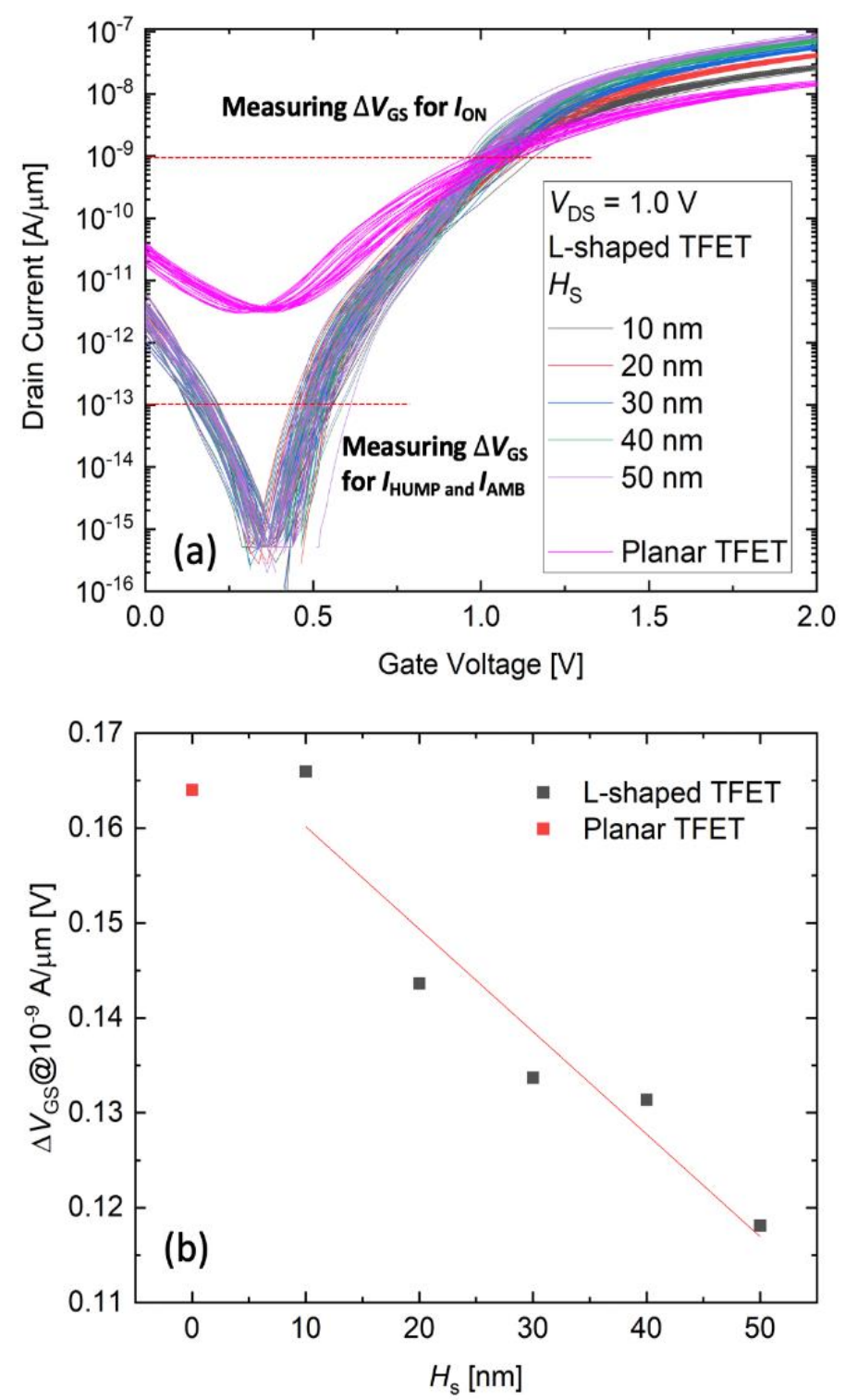

Figure 2. (a) Transfer curves of the L-shaped TFET. In each case of $H_{\mathrm{S}}, 30$ random samples for WFV are generated. (b) Dependency on $H_{\mathrm{S}}$ and $I_{\mathrm{ON}}$ variation. 


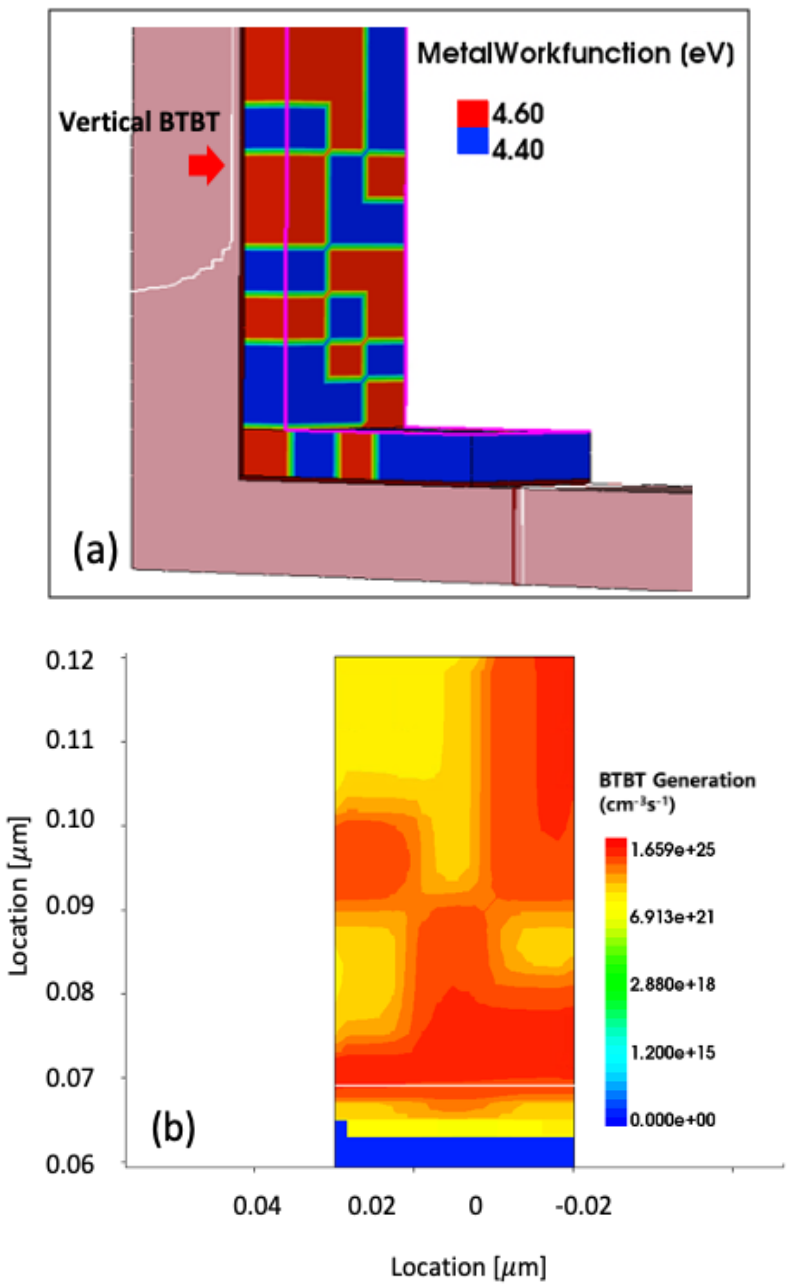

Figure 3. (a) TiN-grains distribution in gate area (b) BTBT rate on source region. The vertical-BTBT generated in the source area can be found to be high.

Next, the $I_{\text {HUMP }}$ variation is investigated. For $I_{\mathrm{HUMP}}$, as reported in the previous papers, the L-shaped TFET has vertical-BTBT and lateral-BTBT [37-39]. The lateral-BTBT is formed at low gate bias $\left(V_{\mathrm{GS}}\right)$ due to low $V_{\mathrm{T}}$, resulting in a hump phenomenon. As shown in Figure $4 \mathrm{a}$, the variation of $I_{\text {HUMP }}$ is extracted from Figure $2 \mathrm{a}$ at $10^{-13} \mathrm{~A} / \mu \mathrm{m}$ of $I_{\mathrm{D}}$ and it shows similar variations regardless of the change in the $H_{S}$ value. To confirm this, we investigate two cases where the hump effect is high and low (Figure $4 \mathrm{~b}$ ). In the transfer curves, the two samples have almost the same $I_{\mathrm{ON}}$ values, while the samples have different $I_{\text {HUMP }}$ values. For the sample with a high hump effect shown in Figure 4c, a high BTBT occurs mainly at the edge of the source area (Figure 4e). On the contrary, for the sample with a low hump effect shown in Figure 4d, a low BTBT is confirmed (Figure 4f). Specifically, the lateral-BTBT is measured highly where $4.4 \mathrm{eV}$ grain is located in the source edge region, which causes a hump effect. As a result, the hump phenomenon is not related to the intrinsic Si area because tunneling occurs only at the edge of the source region.

Finally, the variation of the $I_{\mathrm{AMB}}$ is investigated. As shown in Figure $5 \mathrm{a}$, the variation of $I_{\mathrm{AMB}}$ is extracted from Figure $2 \mathrm{a}$ at $10^{-13} \mathrm{~A} / \mu \mathrm{m}$ of $I_{\mathrm{D}}$. For $I_{\mathrm{AMB}}$ variation, little dependency on the L-shaped TFET is shown with $H_{\mathrm{S}}$ values. To confirm this, we investigate two cases where the hump effect is high and low (Figure $5 b$ ). In the transfer curves, it shows almost the same current in all regions except the $I_{\mathrm{AMB}}$. As a result of confirming the high and low $I_{\mathrm{AMB}}$ samples (Figure $5 \mathrm{c}, \mathrm{d}$ ), it can be found that the BTBT occurs mainly in the edge of the drain at the gate, where there is a $4.6 \mathrm{eV}$ grain (Figure $5 \mathrm{e}$, Figure 5f). 
In conclusion, the L-shaped TFET could be a solution to reduce $I_{\mathrm{ON}}$ variation for WFV in TFET. However, the WFV reduction effect is not seen on whole electrical performance, especially for the $I_{\mathrm{HUMP}}$ and $I_{\mathrm{AMB}}$. These parameters are only affected by the edge region of the gate. Thus, for the real application of the L-shaped TFET, the WFV improvement should proceed through simultaneous applications of gate underlap technology that can reduce $I_{\mathrm{AMB}}$ and the dual WF gate, reducing the $I_{\text {HUMP }}[25,40,41]$.
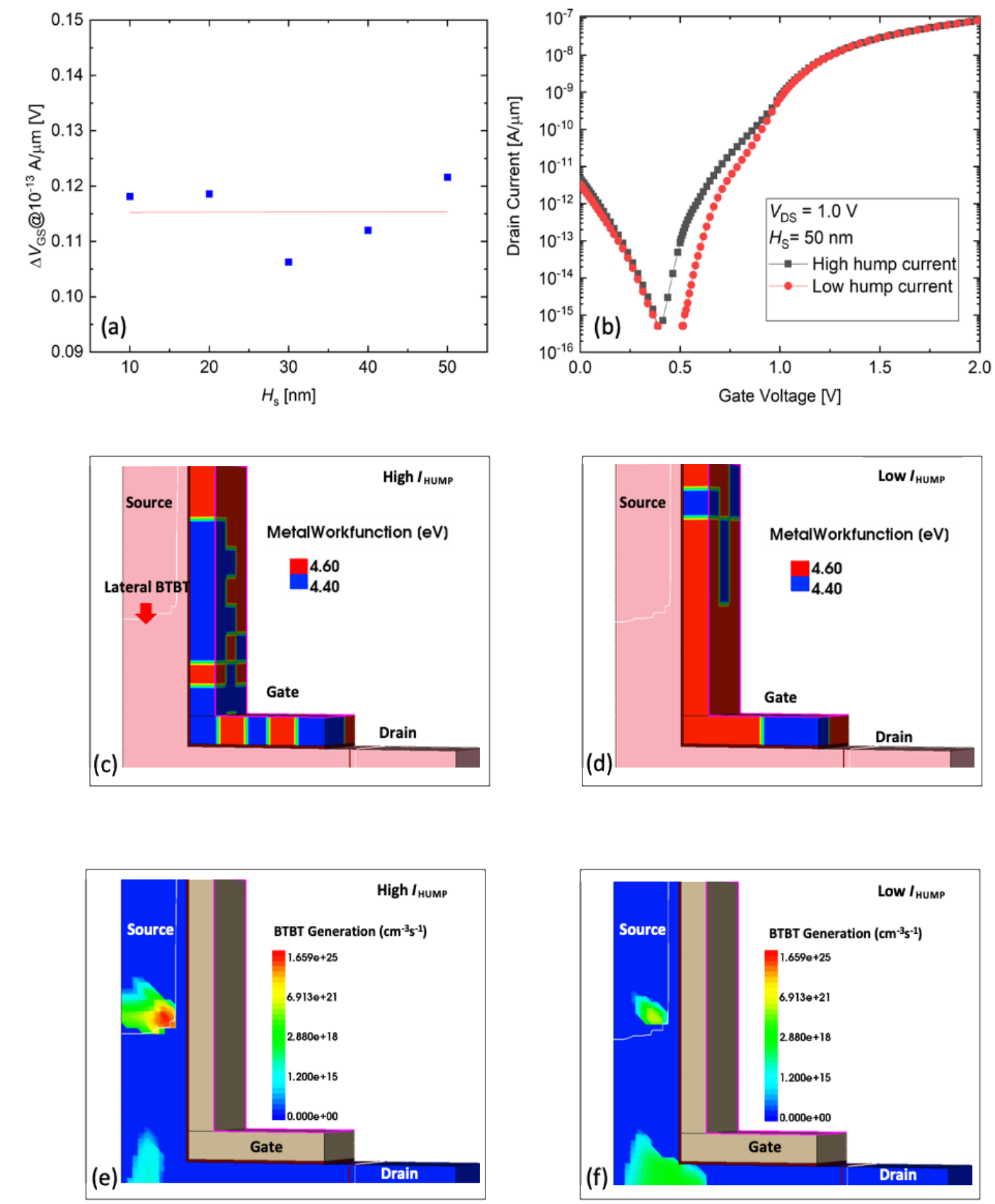

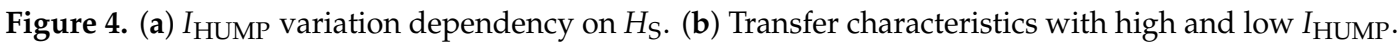
TiN-grains distribution in gate area for (c) high $I_{\text {HUMP }}$ sample and (d) low $I_{\text {HUMP }}$ sample. BTBT rate for (e) high $I_{\text {HUMP }}$ sample and (f) low $I_{\text {HUMP }}$ sample. 

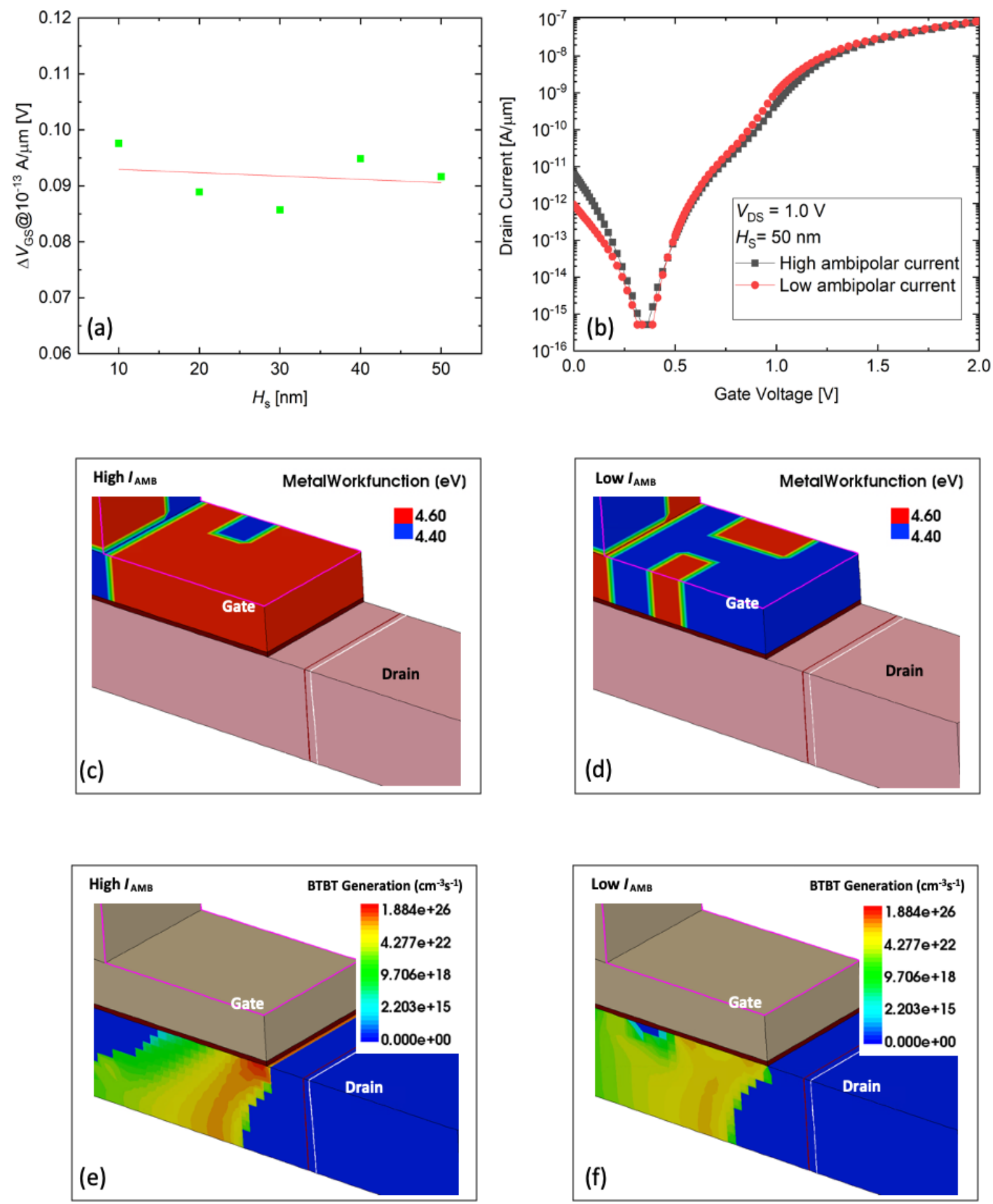

Figure 5. (a) $I_{\mathrm{AMB}}$ variation dependency on $H_{\mathrm{S}}$. (b) Transfer curves with high and low $I_{\mathrm{AMB}}$. TiN-grains distribution in gate area for (c) high $I_{\mathrm{AMB}}$ sample and (d) low $I_{\mathrm{HUMP}}$ sample. BTBT rate for (e) high $I_{\text {HUMP }}$ sample and (f) low $I_{\mathrm{AMB}}$ sample.

\section{Conclusions}

In this paper, the L-shaped TFET is investigated for WFV. We investigate all the variations divided into $I_{\mathrm{ON}}, I_{\mathrm{HUMP}}, I_{\mathrm{AMB}}$ and study each variation. The improved results are shown for WFV in the L-shaped TFET versus the planar TFET because the L-shaped TFET uses the wide tunnel barrier region. Based on these results, it was confirmed that increasing the tunnel area in the TFET device can be a method to decrease WFV. Therefore, the $I_{\mathrm{ON}}$ variation could be reduced by an increase in the 
tunneling region. However, the $I_{\mathrm{HUMP}}$ and $I_{\mathrm{AMB}}$ variations are relatively irrelevant to the size of the tunneling region.

Author Contributions: Writing-Original Draft \& Data curation, J.H.K.; Writing-Review \& Editing, H.W.K.; Validation, Y.S.S.; Supervision S.K. and G.K. All authors have read and agreed to the published version of the manuscript.

Funding: This research was supported in part by the MOTIE/KSRC under Grant 10080575 (Future Semiconductor Device Technology Development Program), and in part by the NRF of Korea funded by the MSIT under Grant NRF-2019M3F3A1A03079739, NRF-2019M3F3A1A02072091 (Intelligent Semiconductor Technology Development Program), NRF-2020R1G1A1007430 and NRF-2020M3F3A2A01081672, and in part by 2019 Research Fund of Myongji University. The EDA tool was supported by the IC Design Education Center (IDEC), Korea.

Conflicts of Interest: The authors declare no conflict of interest.

\section{References}

1. Kim, S.W.; Kim, J.H.; Liu, T.J.K.; Choi, W.Y.; Park, B.G. Demonstration of L-Shaped Tunnel Field-Effect Transistors. IEEE Trans. Electron Devices 2016, 63, 1774-1778. [CrossRef]

2. Kim, S.W.; Choi, W.Y.; Sun, M.C.; Kim, H.W.; Park, B.G. Design guideline of Si-based L-shaped tunneling field-effect transistors. Jpn. J. Appl. Phys. 2012, 51, 06FE09. [CrossRef]

3. Kim, J.H.; Kim, S.W.; Kim, H.W.; Park, B.G. Vertical type double gate tunnelling FETs with thin tunnel barrier. Electron. Lett. 2015, 51, 718-720. [CrossRef]

4. Yang, Z. Tunnel Field-Effect Transistor with an L-Shaped Gate. IEEE Electron Device Lett. 2016, 37, 839-842. [CrossRef]

5. Xie, H.; Liu, H.; Han, T.; Li, W.; Chen, S.; Wang, S. TCAD simulation of a double L-shaped gate tunnel field-effect transistor with a covered source-channel. Micro Nano Lett. 2020, 15, 272-276. [CrossRef]

6. Jeyanthi, J.E.; Arunsamuel, T.S. Heterojunction Tunnel Field Effect Transistors-A Detailed Review. In Proceedings of the ICDCS 2020-2020 5th International Conference on Devices, Circuits and Systems, Coimbatore, India, 5-6 March 2020; pp. 326-329.

7. Asra, R.; Shrivastava, M.; Murali, K.V.R.M.; Pandey, R.K.; Gossner, H.; Rao, V.R. A tunnel FET for VDD scaling below $0.6 \mathrm{v}$ with a CMOS-comparable performance. IEEE Trans. Electron Devices 2011, 58, 1855-1863. [CrossRef]

8. Gandhi, R.; Chen, Z.; Singh, N.; Banerjee, K.; Lee, S. CMOS-Compatible vertical-silicon-nanowire gate-all-around P-Type tunneling FETs with $\leq 5-\mathrm{mV} /$ decade subthreshold swing. IEEE Electron Device Lett. 2011, 32, 1504-1506. [CrossRef]

9. Lanuzza, M.; Strangio, S.; Crupi, F.; Palestri, P.; Esseni, D. Mixed Tunnel-FET/MOSFET Level Shifters: A New Proposal to Extend the Tunnel-FET Application Domain. IEEE Trans. Electron Devices 2015, 62, 3973-3979. [CrossRef]

10. Kim, S.W.; Sun, M.C.; Park, E.; Kim, J.H.; Kwon, D.W.; Park, B.G. Improvement of current drivability in high-scalable tunnel field-effect transistors with CMOS compatible self-aligned process. Electron. Lett. 2016, 52, 1071-1072. [CrossRef]

11. Choi, K.M. 32nm high K metal gate (HKMG) designs for low power applications. In Proceedings of the 2008 International SoC Design Conference, Busan, South Korea, 24-25 November 2008; pp. I-68-I-69.

12. Lee, J.; Lee, R.; Kim, S.; Lee, K.; Kim, H.M.; Kim, S.; Kim, M.; Kim, S.; Lee, J.H.; Park, B.G. Surface Ge-rich p-type SiGe channel tunnel field-effect transistor fabricated by local condensation technique. Solid. State. Electron. 2020, 164, 107701. [CrossRef]

13. Betti Beneventi, G.; Gnani, E.; Gnudi, A.; Reggiani, S.; Baccarani, G. Optimization of a pocketed dual-metal-gate TFET by means of TCAD simulations accounting for quantization-induced bandgap widening. IEEE Trans. Electron Devices 2015, 62, 44-51. [CrossRef]

14. Choi, K.M.; Choi, W.Y. Work-function variation effects of tunneling field-effect transistors (TFETs). IEEE Electron Device Lett. 2013, 34, 942-944. [CrossRef]

15. Lee, Y.; Nam, H.; Park, J.D.; Shin, C. Study of work-function variation for high-k/metal-gate Ge-source tunnel field-effect transistors. IEEE Trans. Electron Devices 2015, 62, 2143-2147. [CrossRef]

16. Saha, R.; Bhowmick, B.; Baishya, S. Effect of gate dielectric on electrical parameters due to metal gate WFV in n-channel Si step FinFET. Micro Nano Lett. 2018, 13, 1007-1010. [CrossRef] 
17. Saha, R.; Bhowmick, B.; Baishya, S. Impact of WFV on electrical parameters due to high-k/metal gate in SiGe channel tunnel FET. Microelectron. Eng. 2019, 214, 1-4. [CrossRef]

18. Avci, U.E.; Morris, D.H.; Hasan, S.; Kotlyar, R.; Kim, R.; Rios, R.; Nikonov, D.E.; Young, I.A. Energy efficiency comparison of nanowire heterojunction TFET and Si MOSFET at $\mathrm{Lg}=13 \mathrm{~nm}$, including P-TFET and variation considerations. In Proceedings of the Technical Digest-International Electron Devices Meeting, IEDM, Washington, DC, USA, 9-11 December 2013; pp. 33.4.1-33.4.4.

19. Dadgour, H.; De, V.; Banerjee, K. Statistical modeling of metal-gate work-function variability in emerging device technologies and implications for circuit design. In Proceedings of the IEEE/ACM International Conference on Computer-Aided Design, Digest of Technical Papers, ICCAD, San Jose, CA, USA, 10-13 November 2008; pp. 270-277.

20. Kim, G.; Kim, J.H.; Kim, J.; Kim, S. Analysis of Work-Function Variation Effects in a Tunnel Field-Effect Transistor Depending on the Device Structure. Appl. Sci. 2020, 10, 5378. [CrossRef]

21. Zhang, X.; Li, J.; Grubbs, M.; Deal, M.; Magyari-Köpe, B.; Clemens, B.M.; Nishi, Y. Physical model of the impact of metal grain work function variability on emerging dual metal gate MOSFETs and its implication for SRAM reliability. In Proceedings of the Technical Digest-International Electron Devices Meeting, IEDM, Baltimore, MD, USA, 7-9 December 2009; pp. 1-4.

22. Frye, A.; Galyon, G.T.; Palmer, L. Crystallographic texture and whiskers in electrodeposited tin films. IEEE Trans. Electron. Packag. Manuf. 2007, 30, 2-10. [CrossRef]

23. Kim, G.; Lee, J.; Kim, J.H.; Kim, S. High on-current Ge-channel heterojunction tunnel field-effect transistor using direct band-to-band tunneling. Micromachines 2019, 10, 77. [CrossRef]

24. Kwon, D.W.; Kim, H.W.; Kim, J.H.; Park, E.; Lee, J.; Kim, W.; Kim, S.; Lee, J.H.; Park, B.G. Effects of Localized Body Doping on Switching Characteristics of Tunnel FET Inverters with Vertical Structures. IEEE Trans. Electron Devices 2017, 64, 1799-1805. [CrossRef]

25. Shin, S.S.; Kim, J.H.; Kim, S. L-shaped tunnel FET with stacked gates to suppress the corner effect. Jpn. J. Appl. Phys. 2019, 58, SDDE10. [CrossRef]

26. Kim, S.W.; Choi, W.Y.; Kim, H.; Sun, M.C.; Kim, H.W.; Park, B.G. Investigation on hump effects of L-shaped tunneling filed-effect transistors. In Proceedings of the 2012 IEEE Silicon Nanoelectronics Workshop, SNW 2012, Honolulu, HI, USA, 10-11 June 2012; pp. 1-2.

27. Kim, S.W.; Choi, W.Y. Hump Effects of Germanium/Silicon Heterojunction Tunnel Field-Effect Transistors. IEEE Trans. Electron Devices 2016, 63, 2583-2588. [CrossRef]

28. Kim, J.H.; Kim, S. Study on the nonlinear output characteristic of tunnel field-effect transistor. J. Semicond. Technol. Sci. 2020, 20, 159-162. [CrossRef]

29. Synopsys, Inc. Sentaurus Device User Guide; Synopsys Inc.: Mountain View, CA, USA, 2015. Available online: http://www.sentaurus.dsod.pl/manuals/data/sdevice_ug.pdf (accessed on 14 August 2020).

30. Kane, E.O. Theory of tunneling. J. Appl. Phys. 1961, 32, 83-91. [CrossRef]

31. Biswas, A.; Dan, S.S.; Le Royer, C.; Grabinski, W.; Ionescu, A.M. TCAD simulation of SOI TFETs and calibration of non-local band-to-band tunneling model. Microelectron. Eng. 2012, 98, 334-337. [CrossRef]

32. Biswas, A.; Alper, C.; De Michielis, L.; Ionescu, A.M. New tunnel-FET architecture with enhanced ION and improved Miller Effect for energy efficient switching. In Proceedings of the Device Research Conference-Conference Digest, DRC, University Park, PA, USA, 18-20 June 2012; pp. 131-132.

33. Paasch, G.; Übensee, H. A Modified Local Density Approximation. Electron Density in Inversion Layers. Phys. Status Solidi 1982, 113, 165-178. [CrossRef]

34. Singh, S.; Raj, B. Vertical Tunnel-FET Analysis for Excessive Low Power Digital Applications. In Proceedings of the ICSCCC 2018-1st International Conference on Secure Cyber Computing and Communications, Jalandhar, India, 15-17 December 2018; pp. 192-197.

35. Ji, S.; Kim, H.; Cho, I.H. Characteristics of recess structure tunneling field effect transistor for high on current drivability. J. Semicond. Technol. Sci. 2018, 18, 360-366. [CrossRef]

36. Jhaveri, R.; Nagavarapu, V.; Woo, J.C.S. Effect of pocket doping and annealing schemes on the source-pocket tunnel field-effect Transistor. IEEE Trans. Electron Devices 2011, 58, 80-86. [CrossRef]

37. Low, K.L.; Zhan, C.; Han, G.; Yang, Y.; Goh, K.H.; Guo, P.; Toh, E.H.; Yeo, Y.C. Device physics and design of a L-shaped germanium source tunneling transistor. Jpn. J. Appl. Phys. 2012, 51, 02BC04. [CrossRef] 
38. Li, C.; Zhao, X.; Zhuang, Y.; Yan, Z.; Guo, J.; Han, R. Optimization of L-shaped tunneling field-effect transistor for ambipolar current suppression and Analog/RF performance enhancement. Superlattices Microstruct. 2018, 115, 154-167. [CrossRef]

39. Lee, S.H.; Park, J.U.; Kim, G.; Jee, D.W.; Kim, J.H.; Kim, S. Rigorous study on hump phenomena in surrounding channel nanowire (SCNW) tunnel field-effect transistor (TFET). Appl. Sci. 2020, 10, 3596. [CrossRef]

40. Anghel, C.; Gupta, A.; Amara, A.; Vladimirescu, A. 30-nm tunnel FET with improved performance and reduced ambipolar current. IEEE Trans. Electron Devices 2011, 58, 1649-1654. [CrossRef]

41. Kim, H.W.; Kim, J.P.; Kim, S.W.; Sun, M.C.; Kim, G.; Kim, J.H.; Park, E.; Kim, H.; Park, B.G. Schottky barrier tunnel field-effect transistor using spacer technique. J. Semicond. Technol. Sci. 2014, 14, 572-578. [CrossRef]

(C) 2020 by the authors. Licensee MDPI, Basel, Switzerland. This article is an open access article distributed under the terms and conditions of the Creative Commons Attribution (CC BY) license (http://creativecommons.org/licenses/by/4.0/). 